\title{
Simulation of Boiler Helical Inner Ribbing Surface Tubular Working
}

\author{
Yaroslav Kosmatskiy ${ }^{1 *}$, Vitaly Lychakov ${ }^{2}$ \\ ${ }^{1}$ The Russian Research Institute of the Tube \& Pipe Industries, Joint Stock Company (RUSNITI JSC); 30, Novorossijskaya \\ Str., Chelyabinsk 454139, Russia \\ ${ }^{2}$ I.I. Polzunov Scientific and Development Association on Research and Design of Power Equipment, Joint Stock Company \\ (NPO CKTI); 3/6, Atamanskaya Str., St. Petersburg, 191167, Russia
}

Corresponding Author Email: Kosmatski@ rosniti.ru

https://doi.org/10.18280/ti-ijes.650103

Received: 10 October 2020

Accepted: 23 January 2021

\section{Keywords:}

simulation, computer modeling, boiler tubular, pipe with helical inner ribbing surface, SolidWorks, heat exchange tubes, linear regression function

\begin{abstract}
The article presents the results of modeling the process of operation of seamless hotextruded pipes with helical inner ribbing of the inner surface. The modeling was carried out in the CAD software SolidWorks using the integrated calculation module Flow Simulation. After modeling and finding the coefficients of the linear regression function, the corresponding equations were obtained for calculating the hydrodynamic and kinematic parameters of the water-steam mixture flow.
\end{abstract}

\section{INTRODUCTION}

Finned pipes for heat exchangers are used in various fields: heating and air conditioning of residential premises and outbuildings, mechanical engineering, the oil industry, nuclear power [1-11].

Due to their special design, heat exchange tubes allow quick and efficient cooling of the coolant, thereby increasing the internal surface area and the heat transfer coefficient.

\section{METHOD FLOW}

Three-dimensional solid models of hot-extruded pipes with an outer diameter of $60.0 \mathrm{~mm}$ and a wall thickness of $6.0 \mathrm{~mm}$ were created in the amount of 49 pieces.

Sketches of cross-sections of ribs were placed at the same distance from each other when constructing helical ribbing of pipes.

Figure 1 shows, as an example, a solid model of a pipe with a ribbing of the inner surface, consisting of twelve ribs.

The angle of rise of the rib in the models varies from $0^{\circ}$ (plain tube) to $45^{\circ}$ in $15^{\circ}$ increments. The higher the angle of rise, the more turns can fit along the length of the pipe. Figure 2 shows a longitudinal section of a pipe with a designation for the elevation angle to represent this parameter.

Computer simulation of the operation process of seamless hot-extruded pipes with helical ribbing of the inner surface in the CAD software SolidWorks using the integrated calculation module Flow Simulation [11-13] has been performed. Numerical values of the hydrodynamic and kinematic parameters of the process are obtained.

Geometry tools in the SolidWorks software make it easy to create ribbing on the inner surface of a pipe and to vary the angle of elevation of the rib by changing the step size.

The next step after creating three-dimensional solid models of pipes with helical ribbing of the inner surface is to set the process parameters and carry out computer modeling.

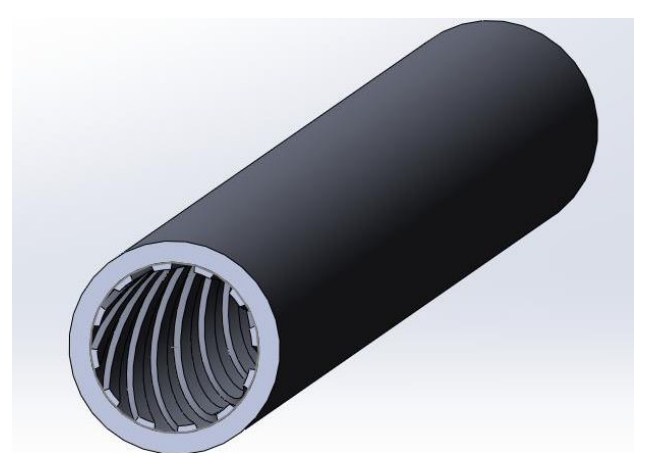

Figure 1. Solid model of pipe with helical inner ribbing surface

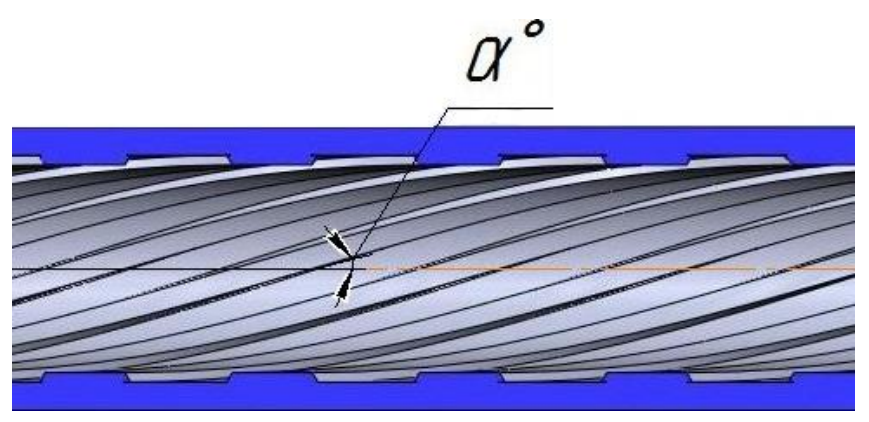

Figure 2. Longitudinal section of the pipe with helical inner ribbing surface: $\alpha^{\circ}-$ rib angle

Computer models of the operation process of seamless hotextruded pipes with helical ribbing of the inner surface were simulated in the SolidWorks software environment using the integrated calculation module Flow Simulation. 


\section{EXPERIMENTAL PART}

The main parameters of the modeling process are shown in Table 1. For each of the 49 models, the same input parameters were set. Each pipe was modeled with two heat carriers watersteam mixture.

Table 1. Initial data for computer modeling

\begin{tabular}{ccc}
\hline № & Parameter & Value \\
\hline 1 & Pipe material & Steel 20 \\
2 & Pipe length & $500 \mathrm{~mm}$ \\
3 & Surface roughness & $60 \mathrm{mcm}$ \\
4 & Ambient temperature & $40^{\circ} \mathrm{C}$ \\
5 & Initial pipe body temperature & $20^{\circ} \mathrm{C}$ \\
6 & Flow temperature & $160{ }^{\circ} \mathrm{C}$ \\
7 & Flow pressure & $0,156 \mathrm{MPa}$ \\
8 & Flow time & $60 \mathrm{c}$ \\
9 & Heat carrier & water-steam mixture \\
\hline
\end{tabular}

The output parameters of the computer simulation were the hydrodynamic and kinematic characteristics of the coolant flow, as well as the indicators of the change in the temperature of the solid. The output from the modeling process is presented in Table 2.

Table 2. Output data of the modeling process

\begin{tabular}{cccc}
\hline № & Parameter & Symbol & Dimension \\
\hline 1 & Heat transfer coefficient & $\alpha_{2}$ & $\mathrm{~W} / \mathrm{m}^{2} \cdot \mathrm{K}$ \\
2 & Solid temperature (max.) & $T_{S}$ & ${ }^{\circ} \mathrm{C}$ \\
3 & Heat dissipation power & $N_{h t}$ & $\mathrm{~W}$ \\
4 & Specific heat flux & $\eta_{h f}$ & $\mathrm{~W} / \mathrm{m}^{2}$ \\
5 & Friction force & $F_{\text {Tp }}$ & $\mathrm{N}$ \\
6 & Turbulence energy & $E_{T}$ & $\mathrm{~J} / \mathrm{kg}$ \\
& Specific dissipation of the & & \\
7 & energy of pulsating motion & $\rho_{\varepsilon}$ & $\mathrm{W} / \mathrm{kg}$ \\
& under the action of viscosity & & \\
\hline
\end{tabular}

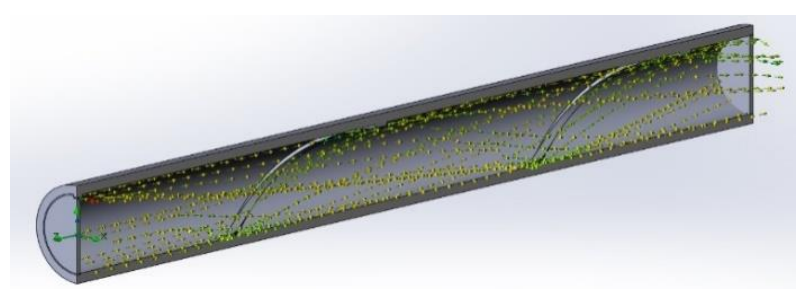

(a) Single-start ribbing

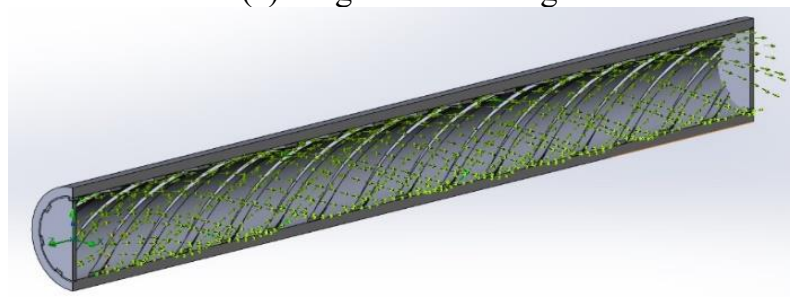

(b) Seven-way ribbing

Figure 3. The nature of the movement of the coolant inside the pipe

The nature of the movement of the coolant inside the pipe is shown in Figure 3. As you can see, the flow is turbulent in nature, which is associated with the peculiarity of the geometry of the pipe, which ensures swirling and creation of vortex motion. With an increase in the number of calls, the flow rate increases, which is shown by the example of pipes shown in Figure $3(a, b)$.

When carrying out computer modeling in the SolidWorks CAD software environment using the integrated calculation module Flow Simulation, the numerical values of the output data presented in Table 2 were obtained.

\section{RESULT PROCESSING}

The key parameters influencing the change in the hydrodynamic and kinematic characteristics of the coolant flow are the number of helical finning entries and the rib elevation angle, varying from 0 to $45^{\circ}$ due to an increase or decrease in the step between the turns of the generatrix, which constitutes the trajectory of motion when constructing the rib geometry.

To determine the equations for calculating the parameters of the process of modeling the operation of seamless hotextruded pipes with helical ribbing of the inner surface, depending on the change in the angle of the rib lift and their number, a regression analysis was carried out.

Due to the sufficient amount of data obtained in the course of computer modeling in the SolidWorks CAD software environment using the integrated calculation module Flow Simulation, it was possible to carry out regression analysis.

An experimental method was used to select the type of regression function.

Based on the principle of minimum complexity to analyze the dependence of each of the output parameters (Table 3) on the number of ribs and their elevation angle, a linear form of the regression function was adopted $-y=b_{0}+b_{1} x+\cdots+$ $b_{n} x_{n}$. The parameters of this function were estimated by the least squares method (OLS) in Microsoft Office Excel.

After finding the coefficients of the linear regression function, the corresponding equations were obtained of the water-steam mixture flow:

$$
\alpha_{2}=830,30-19,82 \cdot K_{\mathrm{p}}+6,65 \cdot \alpha^{\circ},
$$

where, $\alpha_{2}$ - heat transfer coefficient, $\mathrm{W} / \mathrm{m}^{2} \mathrm{~K} ; \mathrm{K}_{\mathrm{p}}$ - number of ribs; $\alpha^{\circ}$ - rib angle;

$$
N_{h t}=-6627,13+284,99 \cdot \mathrm{K}_{\mathrm{p}}-107,62 \cdot \alpha^{\circ} \text {, }
$$

where, $N_{h t}-$ heat transfer power, W;

$$
\eta_{h f}=-122903,309+6008,807 \cdot \mathrm{K}_{\mathrm{p}}-44,258 \cdot \alpha^{\circ},
$$

where $\eta_{h f}-$ specific heat flux, $\mathrm{W} / \mathrm{m}^{2}$;

$$
F_{\mathrm{Tp}}=13,739+0,015 \cdot \mathrm{K}_{\mathrm{p}}+0,21 \cdot \alpha^{\circ},
$$

where, $F_{\text {тр }}-$ friction force, $\mathrm{N}$;

$$
E_{T}=0,678-0,039 \cdot \mathrm{K}_{\mathrm{p}}-0,003 \cdot \alpha^{\circ},
$$

where, $E_{T}$ - turbulence energy, $\mathrm{J} / \mathrm{kg}$;

$$
\rho_{\varepsilon}=258,93-17,10 \cdot K_{\mathrm{p}}-1,25 \cdot \alpha^{\circ},
$$

where, $\rho_{\varepsilon}-$ specific energy dissipation, $\mathrm{W} / \mathrm{kg}$; 


$$
T_{s}=159,87+0,004 \cdot \mathrm{K}_{\mathrm{p}}+0,001 \cdot \alpha^{\circ}
$$

where, $T_{s}$ - maximum temperature of a solid.

The number of fins should increase heat transfer. Therefore, it is planned to correct it in the future and work in this direction.

Comparison of the values calculated by formulas (1) - (7) with the values obtained in the simulation shows that these values have discrepancies within $28 \%$ for the parameters indicated in Table 1 . This means that the selected regression function is adequate.

After finding the coefficients of the linear regression function, the corresponding equations were obtained similarly to Eqns. (1)-(7) for steam flow:

$$
\begin{gathered}
\alpha_{2}=2604,332-139,192 \cdot \mathrm{K}_{\mathrm{p}}-3,024 \cdot \alpha^{\circ}, \\
N_{h t}=-205,247-3,809 \cdot \mathrm{K}_{\mathrm{p}}-10,756 \cdot \alpha^{\circ}, \\
\eta_{h f}=-4667,01+35,613 \cdot \mathrm{K}_{\mathrm{p}}-62,842 \cdot \alpha^{\circ}, \\
F_{\mathrm{Tp}}=0,008-0,0002 \cdot \mathrm{K}_{\mathrm{p}}+0,0002 \cdot \alpha^{\circ}, \\
E_{T}=0,259+0,003 \cdot \mathrm{K}_{\mathrm{p}}+0,0009 \cdot \alpha^{\circ}, \\
\rho_{\varepsilon}=97,592-0,07 \cdot \mathrm{K}_{\mathrm{p}}+0,144 \cdot \alpha^{\circ}, \\
T_{s}=89,090+2,018 \cdot \mathrm{K}_{\mathrm{p}}+1,167 \cdot \alpha^{\circ} .
\end{gathered}
$$

Comparison of the values calculated by formulas (8) - (14) with the values obtained by modeling in the Solid Works software shows that these values have discrepancies within $25 \%$. This means that the selected regression function is adequate.

\section{CONCLUSION}

Computer simulation has been performed computer simulation of the operation process of seamless hot-extruded pipes with helical ribbing of the inner surface in the CAD software SolidWorks using the integrated calculation module Flow Simulation. Numerical values of the hydrodynamic and kinematic parameters of the process are obtained. Equations were obtained based on the data obtained and the performed regression analysis.

The results obtained in the course of the work can be useful for assessing the possible boundaries of intensification of heat transfer and assessing the applicability of pipes for the transfer of various heat carriers.

\section{REFERENCES}

[1] Abramovich, G.N. (2011). The theory of turbulent jets: Reprint reproduction of the 1960 edition - Moscow: EKOLIT, 720.

[2] Monin, A.S. (1965). Statistical fluid mechanics. The mechanics of turbulence, 640 .
[3] Gu, P.D., Cui, Y.J., Wang, L.L., Wang, H., Zhang, H.S., Tao, L. (2011). The performance analysis of longitudinal finned heat pipe applying to air conditioning. International Conference on Multimedia Technology, Hangzhou, China. https://doi.org/10.1109/ICMT.2011.6003200

[4] Cao, Z.J., Zhu, H., Xu, Z.L. (2011). Study on the effects of heat pipe and fins for heat dissipation under natural convection. 2011 International Conference on Consumer Electronics, Communications and Networks (CECNet). https://doi.org/10.1109/CECNET.2011.5768531

[5] Aksenov, A. (2019). Heat Transfer from the Collectively Finned Surface at Different Temperatures of the End Sources. 2019 International Multi-Conference on Industrial Engineering and Modern Technologies (FarEastCon). https://doi.org/10.1109/FarEastCon.2019.8934843

[6] Zhang, Y.H., Wang, L.B., Han, Y.X. (2011). Study of heat transfer performance of tube-fin heat exchanger with interrupted annular groove fin. 2011 International Conference on Consumer Electronics, Communications and Networks (CECNet). https://doi.org/10.1109/CECNET.2011.5768596

[7] Kou, W., Cui, H.G., Fan, G. (2011). Application of BCC algorithm in optimization of plate finned-tube heat exchanger. MSIE 2011. https://doi.org/10.1109/MSIE.2011.5707600

[8] Guan, Y., Cui, H.J., Li, M.H. (2010). The ThermoPerformance Study of Automobile Tube-core-fin Radiator. 2010 WASE International Conference on Information https://doi.org/10.1109/ICIE.2010.75

[9] Khoo, K.L., Sun, C., Lewpiriyawong, N., Lee, P.S., Chou, S.K. (2016). Numerical investigation of the thermalhydraulic performance of finned oblique-shaped tube heat exchanger. 2016 15th IEEE Intersociety Conference on Thermal and Thermomechanical Phenomena in Electronic Systems (ITherm). https://doi.org/10.1109/ITHERM.2016.7517606

[10] Yang, J.M., Wang, B., Ma, R.R., Feng, X. (2011). Numerical study on air-side flow and heat transfer characteristics of steel tube brazing snake-like fins for direct air-cooled condenser. 2011 Second International Conference on Mechanic Automation and Control Engineering. https://doi.org/10.1109/MACE.2011.5987930

[11] Yang, J.M., Wang, B., Ma, R.R., Feng, X. (2011). Numerical study on air-side flow and heat transfer characteristics of steel tube brazing snake-like fins for direct air-cooled condenser. 2011 Second International Conference on Mechanic Automation and Control Engineering. https://doi.org/10.1109/MACE.2011.5987930

[12] Matsson, J.E. (2010). An Introduction to SolidWorks Flow Simulation 2010. SDC Publications, Mission, Kansas (USA), 297.

[13] Alyamovsky, A.A. (2010). Engineering Calculations in SolidWorks Simulation. DMK Press. 